\title{
Novos elementos teóricos sobre o Estado Brasileiro na última década: Análise do governo Lula-Dilma
}

New theoretical elements of the Brazilian State in the last decade: Analysis of the government Lula-Dilma

Nuevos elementos teóricos sobre el Estado brasileño en la última década: Análisis del gobierno Lula-Dilma

Nouveaux éléments théoriques sur l'État brésilien au cours de la dernière décennie: analyse du gouvernement Lula-Dilma

\section{Leda Velloso Buonfiglio}

\section{(2) OpenEdition}

\section{Journals}

\section{Edição electrónica}

URL: http://journals.openedition.org/espacoeconomia/3108

DOI: $10.4000 /$ espacoeconomia.3108

ISSN: 2317-7837

Editora

Núcleo de Pesquisa Espaço \& Economia

Refêrencia eletrónica

Leda Velloso Buonfiglio, « Novos elementos teóricos sobre o Estado Brasileiro na última década: Análise do governo Lula-Dilma », Espaço e Economia [Online], 11 | 2017, posto online no dia 07 abril 2018, consultado o 02 maio 2019. URL : http://journals.openedition.org/espacoeconomia/3108 ; DOI : 10.4000/espacoeconomia.3108

Este documento foi criado de forma automática no dia 2 Maio 2019

(C) NUPEE 


\section{Novos elementos teóricos sobre o Estado Brasileiro na última década: Análise do governo Lula-Dilma}

New theoretical elements of the Brazilian State in the last decade: Analysis of the government Lula-Dilma

Nuevos elementos teóricos sobre el Estado brasileño en la última década: Análisis del gobierno Lula-Dilma

Nouveaux éléments théoriques sur l'État brésilien au cours de la dernière

décennie: analyse du gouvernement Lula-Dilma

Leda Velloso Buonfiglio

\section{NOTA DO AUTOR}

O presente artigo é um subcapítulo da tese intitulada "Da política urbana federal à produção do espaço municipal: a gestão habitacional no Rio Grande do Sul" defendida em fevereiro de 2015, e portanto, tal análise desenvolvida aqui chega até o ano de 2014, abarcando os dois mandatos de Luís Inácio Lula da Silva e o primeiro mandato de Dilma Rousseff.

\section{Introdução}

1 Com o Partido dos Trabalhadores à frente da Presidência da República e à frente de alguns aparelhos de Estado, por mais de uma década, com três mandatos consecutivos iniciados com Luís Inácio Lula da Silva (2003-2010), e que se manteve por sua sucessora Dilma Rousseff (2011-2014) no primeiro mandato, o Estado Brasileiro assistiu à uma condensação material de novas relações de forças, estabelecendo uma nova unidade conflitual de aliança no poder em um novo equilíbrio de compromissos. 
2 Nesse breve ensaio, lançamos mão de referências de autores da teoria marxista do Estado como Nico Poulantzas (1985), Joachim Hirsch (2010), Martin Carnoy (1988) e para compreensão das mudanças ocorridas no Brasil: Paul Singer; André Singer; André R.Teixeira; Whitaker; Marilena Chauí; Boaventura Sousa Santos (2014); Antônio G. Belluzzo; Leda Paulani; Arlete M. Rodrigues, entre outros.

\section{Elementos da política social}

3 No início dos anos de 1980, analisando a estrutura social do Brasil, Paul Singer detectou a emergência do que denominou de "subproletariado", constituído por "empregados domésticos, assalariados de pequenos produtores diretos e trabalhadores destituídos das condições mínimas de participação na luta de classes" (SINGER, 1981, p. 83):

O proletariado, portanto, também se compõe de duas partes: uma empregada pelo capital ou pelo Estado que chamamos de proletariado propriamente dito e outra composta pelos que de fato ou potencialmente oferecem sua força de trabalho no mercado sem encontrar quem esteja disposto a adquiri-la por um preço que assegure sua reprodução em condições normais, constituindo assim um proletariado virtual ou subproletariado. (SINGER, 1981, p. 22).

4 Com base nas quatro corridas eleitorais presidenciais, entre 1989 e 2002, André Singer aponta a contradição mais patente de que, muito embora o PT, em sua origem, representasse a classe trabalhadora e a esquerda brasileira, Lula, a principal liderança do partido, não obteve apoio de classes de baixíssima renda, nem sequer os votos realizados demonstraram uma polarização esperada, sendo que a metade mais pobre da nação pendia para a direita:

Era relativamente claro que havia um poder de veto das classes dominantes, o qual residia na capacidade de mobilizar o voto de baixíssima renda. O que não se distinguia com nitidez eram as raízes ideológicas do mecanismo, embora os levantamentos de opinião indicassem permanente supremacia conservadora na distribuição do eleitorado entre esquerda e direita (...) um desequilíbrio que decorria da inclinação dos eleitores de menor renda para a direita. (SINGER, 2009, p. 89).

5 A principal base de apoio a Lula estava entre os eleitores dos níveis superiores de escolarização nos Estados mais urbanizados e industrializados do Sul e do Sudeste. Uma reorientação política apenas começa a ocorrer e inverter tal polaridade na eleição de 2006 com o "descolamento entre eleitores de baixíssima renda e de classe média". Portanto, apenas após assumir o governo, Lula obteve a adesão do segmento de classe que buscava desde, pelo menos, $198^{1}$.

6 Mais de duas décadas foram preciso para que a nova fração de classe, o subproletariado, se realinhasse politicamente e se identificasse com a classe trabalhadora no projeto político do PT. Mas tal realinhamento e identificação desencadeou no fenômeno social do lulismo, emergindo como uma força nova que transplantou a própria base de sustentação da esquerda brasileira e do PT em eleições anteriores, projetando no presidente Lula sua voz e imagem popular:

Atomizados pela sua inserção no sistema produtivo, necessitam de alguém que possa, desde o alto, receber a projeção de suas aspirações. (...) na ausência de um avanço da esquerda, o primeiro mandato de Lula terminou por encontrar outra via de acesso ao subproletariado, amoldando-se a ele, mais do que o modelando, porém, ao mesmo tempo, constituindo-o como ator político (SINGER, 2009, p. 99). 
7 De fato, deu-se a ascensão desse novo ator político, que se enxergava na imagem de Lula. O subproletariado, até então invisível na arena de lutas, lembrado tão somente como eleitorado fiel por meio de históricas práticas de clientelismo, passa a promover uma mudança na imagem social da classe popular:

A alternância com Lula tinha um sentido adicional e muito concreto para seus eleitores: o de ser, também, uma alternância de classe no centro do sistema, a presidência da república. (...) Por essas razões, a alternância era muito mais que política, envolvendo sentimentos profundos de auto-imagem e amor-próprio. Era uma alternância "deles" por "nós" e por "mim". As primeiras pesquisas feitas logo após o começo do governo captaram uma nítida mudança nas atitudes dos eleitores de classe popular, apontando para o aumento de sua auto-estima e da confiança de que o Brasil iria melhorar (...). A vitória de Lula foi a vitória da noção de que um presidente pode vir do povo. (COIMBRA, 2007, p. 12-13). ${ }^{2}$

Para essa nova fração de classe, consubstanciaram-se políticas sociais:

O pulo do gato de Lula foi, sobre o pano de fundo da ortodoxia econômica, construir uma substantiva política de promoção do mercado interno voltado aos menos favorecidos, a qual, somada a manutenção da estabilidade, corresponde nada mais nada menos que a realização de um completo programa de classe. (SINGER, 2009, p. 98).

9 André Singer (2009) sintetiza, portanto, uma valiosa contribuição para a análise política brasileira nos últimos anos que traz à tona uma fração de classe e um programa de classe a partir de pelo menos três novos elementos sociais que se inscrevem na teoria do Estado Brasileiro: a ascensão de uma fração de classe, o subproletariado (agora com visibilidade e representação); um novo realinhamento político (ainda que com um esvaziamento da dimensão ideológica); e a incidência de políticas sociais pelo Estado.

Revisitando a teoria, para Nico Poulantzas (1985), o Estado abarca todas as classes sociais. No interior do Estado há fissuras, por onde podem conflitar interesses antagônicos. Nesse sentido, as classes populares dominadas (divididas e/ou desorganizadas) estão e sempre estiveram presentes no Estado, e devido à existência de lutas populares é que ocorrem divisões e contradições no interior do Estado: "na realidade, as lutas populares atravessam o Estado de lado a lado", e atravessam seus aparelhos. Portanto, para Poulantzas as lutas populares não são algo externo que cerca, assedia e pressiona o Estado do lado de fora; do contrário, são internas a ele e estão inscritas na trama do Estado. Não são as lutas que são absorvidas ou incluídas pelo Estado, mas “é o Estado que está imerso nas lutas que o submergem" (Poulantzas, 1985, p. 162).

11 Quando o autor desenvolve a famosa noção de autonomia relativa do Estado, está em realidade refutando, por conseguinte, a concepção instrumentalista de que o Estado é coisificado, instrumentalizado e manipulado apenas por interesses da classe dominante. A autonomia relativa diz respeito à relação do Estado com frações do bloco no poder ${ }^{3}$ para assegurar o interesse geral da burguesia (classe dominante) e a própria organização e unificação do Estado na célebre citação: “O Estado é a condensação material das relações de força (...) entre classes e frações de classes” (POULANTZAS, 1985, p. 30).

12 Assim, o Estado, para Poulantzas, é uma arena de lutas onde se inscrevem e se condensam as lutas de classe. Ao Estado cabe, portanto, uma função de organização e mediação das classes sociais em disputa, o que termina em constituir uma unidade conflitual de aliança de poder e de um "equilíbrio instável" dos compromissos entre seus componentes. Desta perspectiva, o Estado atua na mediação dos conflitos entre as classes dominantes e 
dominadas, dividindo e desorganizando as massas, mas, simultaneamente, comprometendo-se com muitas de suas demandas (CARNOY, 1988, p. 161).

Ainda que hoje não se possa analisar integralmente o alcance real das políticas sociais implantadas na última década pelo Estado brasileiro pode-se afirmar, seguramente, que na última década as classes populares foram "objeto de medidas de atendimento social" (HIRSCH, 2010) e seus interesses e orientações se materializaram em diversos campos das políticas públicas. Além do Programa Bolsa Família (PBF), houve o aumento real de 24,25\% no salário mínimo durante o primeiro mandato, em maio de 2005, cujo impacto foi mais abrangente do que aquele Programa. De forma combinada, o Bolsa Família e a elevação do salário mínimo, dinamizaram as economias locais menos desenvolvidas. Outra possibilidade aberta aos aposentados, às vezes principal fonte de recursos em pequenas comunidades, foi o uso do crédito consignado ${ }^{4}$ que permitiu o financiamento popular, incluindo um aumento expressivo do empréstimo à agricultura familiar, do microcrédito e da bancarização de pessoas de baixíssima renda (SINGER, 2009).

Entre os ganhos sociais mais significativos deve-se incluir o maior acesso ao trabalho, assim como as políticas distributivas e reestruturadoras da base econômica local, em especial no Norte e Nordeste (WHITAKER, 2014, s/p) . Outras demandas sociais foram pautadas e têm trazido, paulatinamente, mudanças estruturais na sociedade, como as cotas, a ruptura da indústria do vestibular, com maior acesso às Universidades Públicas (pelo Exame Nacional do Ensino Médio - ENEM, na esteira do Programa Universidade para Todos - PROUNI) e aspectos do emponderamento da mulher pelo PBF (e acrescenta-se aqui, pelo Programa Minha Casa, Minha Vida) (CHAUÍ, 2013).

O Estado institucionaliza e condensa no interior de seus aparelhos uma relação com todas as classes sociais, pactuando com certos interesses das classes populares. Mais que isso, as relações das classes populares se institucionalizaram em aparelhos estatais que, funcionam como contraponto às demais estruturas que, tradicionalmente, têm servido como pontos de apoio de setores das classes dominantes (HIRSCH, 2010). A aparelhagem do Estado deve servir justamente para mediar tais divergências e o estabelecimento dos compromissos ${ }^{6}$. Isso significa que as classes dominantes cristalizam um poder próprio (por aparelhos ou setores no interior do Estado), enquanto as classes dominadas apresentam apenas focos de oposição ao poder (Poulantzas, 1985, p. 164).

Hirsch (2010) explicita a heterogeneidade dos aparelhos do Estado analisando sua relação com as classes populares e cita, como exemplo aparelhos como Ministérios da Assistência Social ou do Trabalho, nos quais os interesses das classes dominadas podem, em certa medida e de forma subordinada, materializar-se:

o fato de que o Estado apresente uma teia de relações sociais e de classe s expressase na heterogeneidade de seus aparelhos. Ele não é uma unidade organizativa fechada, mas desmembra-se em instâncias relativamente autônomas frequentemente em concorrência e mesmo em disputa entre si. Nelas sempre se manifestam relações sociais e de classe próprias, seja quando elas agem como ponto de apoio de classes ou de parte de classes, seja sob a forma de agências que se relacionam com as classes dominadas e cujos interesses incluem-se nos mecanismos estatais de decisão. (HIRSCH, 2010, p. 38).

17 De fato, em consonância à teoria anunciada, destaca-se a criação de diversos Ministérios como o do Desenvolvimento Social e Combate à Fome (MDS), com políticas nacionais de desenvolvimento social, segurança alimentar e nutricional, assistência social e programas de transferência de renda. De modo geral, esse Ministério tem feito um contraponto ao crescimento econômico capitalista sem desenvolvimento social. Da mesma forma, a 
criação do Ministério do Desenvolvimento Agrário (MDA) pode ser considerada um contraponto ao Ministério da Agricultura.

o Ministério das Cidades representou a institucionalização de uma das bandeiras históricas do PT, explicitada já pelo Projeto Moradia na campanha presidencial de 2002, e deu inteligibilidade ao nível de análise e à escala do urbano, com articulação inédita entre as políticas urbanas setoriais, com especial enfoque para a habitação popular. Como pontuou Boaventura Sousa Santos ${ }^{7}$, um ciclo ascendente de inclusão social que difere e destoa o Brasil de países da Europa que, justamente, vêm de um ciclo de exclusão social bastante contundente e rápido, motivado pela crise econômica e financeira.

Ficou patente, contudo, que no período analisado, a inclusão social que, de fato, promoveu mudanças importantes se deu mais pela rota do consumo do que pelo caminho da transformação de valores éticos:

O aumento da capacidade de consumo, que, no fundo, foi o motor do lulismo, talvez tenha, isto sim, amplificado ainda mais o pensamento fútil, as interpretações rasas e a intolerância, típicas de uma sociedade que se move pela religião do consumismo, por natureza a cristalização do individualismo, da competição, do desprezo àquele que "não tem", ou seja, ao mais pobre. (WHITAKER, 2014, s/p).

Trata-se antes da elevação de renda e aumento da base assalariada com capacidade de consumo e não do que vem sendo chamado erroneamente de "nova classe média"8 ${ }^{\text {, afinal: }}$

Formar classe média consumidora não é tudo e a aposta na melhoria da renda das faixas médias e do seu acesso ao consumo aquece, ao mesmo tempo, uma economia demasiadamente liberal e altamente destruidora (citemos, por exemplo, o poder exacerbado do setor financeiro, a destruição da Amazônia ou o papel predador, no campo, do "agrobusiness)". Se [o aumento da base assalariada] por um lado abre para muitos o "fantástico" mundo do consumo, ele não garantiu em nada, por outro lado, uma alteração dos valores éticos e comportamentais da nossa sociedade, nem uma mudança repentina de classe social dos beneficiados pelo aumento da oferta de trabalho. Pelo contrário, os valores éticos que predominam na nossa classe-média parecem ainda ser aqueles inculcados pelo regime militar, da mediocridade cultural, da aceitação robótica das informações da mídia, da passividade cívica e da alienação política. Portanto, não se alteraram os fundamentos éticos da sociedade nem a lógica da política. (WHITAKER, 2014, s/p).

\section{Elementos da política econômica}

21 Será necessário, ainda, compreender o pano de fundo da ortodoxia econômica (SINGER, 2009) do período analisado, culminando em uma nova reorientação nos últimos anos do primeiro mandato de Dilma Rousseff. Durante o governo de FHC (duas gestões), o bloco no poder que se consolidou foi a fração bancário-financeira do capital, que havia se iniciado desde o governo Fernando Collor, cujos interesses estavam ligados ao mercado financeiro, doméstico e internacional, representados por postos-chave no comando da política econômica ${ }^{9}$. De acordo com R. A. Teixeira ${ }^{10}$, essa fração capitalista se sobrepunha às demais, em especial aos segmentos do capital produtivo e à economia brasileira:

foi lançada em um novo tipo de dependência que contava com a era dos fluxos de capital volátil, fundamentais para manter a estabilidade do arranjo macroeconômico então vigente: conter a inflação pela âncora cambial, ou seja, mantendo a taxa de câmbio sobrevalorizada para baratear as importações. (TEIXEIRA, 2014, s/p). 
22 A dependência financeira do país perante os fluxos internacionais de capital de curto prazo, que o autor acima aponta, não pode ser analisada como um fenômeno isolado no capitalismo global, e assim como outros países onde os mercados financeiros "lograram capturar os controles da economia e do Estado, mediante o aumento do seu poder social". A lógica desse novo poder reside em sua "capacidade de impor vetos às políticas macroeconômicas" e as ações dos governos sofrem fortes resistências das "casamatas instaladas nos quartéis da finança contemporânea" (BELLUZZO, 2014, s/p).

Em que pesem a oposição ferrenha e as duras críticas da esquerda, os embates e disputas no interior do partido, o governo Lula se inicia com um viés conservador no campo da política macroeconômica (SADER, 2007) e, durante os anos iniciais, a dependência econômica financeira prevaleceu pela "linha de menor resistência" contra os interesses estabelecidos, permanecendo a hegemonia ${ }^{11}$ da fração bancário-financeira do capital no interior do bloco no poder (TEIXEIRA, 2014, s/p) ${ }^{12}$.

Contudo, a cartilha neoliberal fora sendo rompida paulatinamente. Mudanças de peso começaram a ocorrer com novos grupos de interesses da fração capitalista, que se articularam e ganharam espaço, como a "ala desenvolvimentista", "abrindo caminho para uma política fiscal mais preocupada com a aceleração do crescimento e com a distribuição da renda, com os gastos sociais e uma política de elevação do salário mínimo". Esse momento se cristaliza com o lançamento do Programa de Aceleração do Crescimento PAC (TEIXEIRA, 2014, s/p).

A situação internacional estava favorável "com a calmaria nos mercados financeiros internacionais e elevação dos preços das commodities exportadas pelo Brasil, aliada à estratégia do governo de acúmulo de reservas internacionais". Sabe-se que, em uma crise financeira internacional de grandes proporções como a de 2008, o Estado é quem socorre o mercado e, de forma análoga, o Governo Federal Brasileiro, em 2009, criou o PMCMV, "salvando" o país da crise, com investimentos e aplicação de fartos recursos na construção civil. O Programa foi proposto pelo Ministério da Fazenda, e logo vinculou a política urbana e habitacional do Ministério das Cidades à economia nacional em um Programa que deu escala à produção de unidades habitacionais prontas ${ }^{13}$.

A crise internacional de 2008 ajudou a fortalecer a nova composição de forças do bloco no poder do Estado Brasileiro:

Um conjunto de estímulos como redução de juros, expansão do crédito dos bancos públicos e do crédito habitacional pelo programa Minha Casa Minha Vida, continuidade da elevação real do salário mínimo e dos investimentos públicos planejados no âmbito do PAC e redução da meta de superávit primário, permitiu que a economia brasileira se recuperasse da crise mais rapidamente que vários outros países, e após uma leve queda de $0,2 \%$ do PIB em 2009, auge da crise no Brasil, cresceu 7,5\% em 2010, último ano do presidente Lula, com manutenção da renda e do emprego. (TEIXEIRA, 2014, s/p).

27 Após a crise internacional de 2008 , continuou a redução da influência e perda da hegemonia da fração de classe bancário-financeira.

A reversão do padrão dos fluxos de capital que, nas crises anteriores, originadas nos "mercados emergentes", tendiam a fugir abruptamente dos países periféricos em direção ao dólar, e nesta crise fizeram o caminho inverso, permitiu que o Brasil pudesse fazer uso de uma política macroeconômica expansionista para incentivar a atividade econômica, com reduções substantivas da taxa de juros e expansão fiscal, a contragosto dos representantes do sistema financeiro. O governo Dilma consolidaria esta perda da hegemonia, cujo momento mais simbólico foi o discurso 
da presidenta no 1. de maio de 2012, Dia do Trabalhador, anunciando em cadeia nacional que os bancos públicos iam travar uma batalha pela redução dos spreads bancários. (TEIXEIRA, 2014, s/p).

Foi no governo petista de Dilma Rousseff que sinais claros de enfraquecimento da hegemonia da fração de classe bancário-financeira foram dados, com a adoção de medidas de enfrentamento direto - que seriam impensáveis alguns anos antes - por parte do governo, como a queda da taxa Selic e a redução das taxas de juros dos bancos públicos ${ }^{14}$ (TEIXEIRA, 2014; PAULANI, 2014 $4^{15}$ ). Assim, por fim no Brasil, os economistas apontam uma heterodoxia econômica "para horror dos mercados financeiros" no presente governo petista de Dilma Rousseff:

A presidenta Dilma não conta com o apreço dos mercados financeiros. Ao longo de sua trajetória na cadeira de presidente, ela foi se afastando da cartilha ortodoxa que detinha ainda grande peso no governo (daí a inexistência de terrorismo econômico nas duas eleições seguintes) e tomando decisões pouco palatáveis para os interesses representados por esses mercados. A começar pela troca de comando do Banco Central, a presidenta teve a coragem de enfrentar o lobby bancário-financeiro, não só reduzindo a Selic, como utilizando os bancos públicos para forçar a queda dos vergonhosos spreads bancários, que ainda assim continuam muito altos. A heterodoxia econômica, que havia ficado completamente escanteada no início do período de 12 anos de gestão do governo federal sob o comando do PT, foi ganhando espaço no governo da presidenta, para horror dos mercados financeiros, que agora escutam estarrecidos pela voz do atual ministro chefe da Casa Civil, Aloísio Mercadante, que não será dada nenhuma guinada ortodoxa no segundo mandato da presidenta. (PAULANI, 2014, s/p).

Claro que essas medidas implicaram consequências políticas, como a perda de apoio da fração bancário-financeira ao governo, e que, contudo, no atual cenário político brasileiro busca novamente sua condição de fração hegemônica no interior do bloco no poder, o que nos remeteria invariavelmente no interior da teoria marxista do Estado à questão da legitimidade em Gramsci ${ }^{16}$, tema para outro artigo.

\section{Nova Agenda Política e Social: Questões em Aberto}

30 Há um novo equilíbrio de forças e de bloco no poder, assinalado com agendas antagônicas de compromissos sociais (voltados às classes populares) e econômicos (voltados às classes dominantes) que dão lugar a conflitos intensos, pelos quais se reabrem velhas fissuras: na demarcação de terras indígenas; na construção de novas hidroelétricas em território de comunidades ribeirinhas; nas cidades de exceção equipadas para a Copa do Mundo (VAINER, 2013); e na perpetuação da produção do espaço moderno de shoppings centers, edifícios de alto padrão, loteamentos murados, condomínios fechados. Assim, a nova unidade conflitual de aliança de poder inclui e abarca as classes populares, mas sem as contemplar única e integralmente.

31 As lutas populares não se esgotaram nem cessaram e continuam atravessando o Estado Brasileiro e seus aparelhos como causas históricas reclamadas, atualizando a teoria de Poulantzas (1985). Para além das ruas, e dos movimentos de massa, um fenômeno importante se processou nos últimos anos, com lideranças de classes populares absorvidas na aparelhagem estatal, moldando, uma vez mais, e atestando o caráter heterogêneo dos aparelhos de Estado. A nova configuração institucional da última década capturou parte das lutas dos movimentos populares organizados e deles se apropriou, 
trazendo para o poder público lideranças e agentes políticos das ruas, sindicatos e ONGs, invertendo e mesclando os papéis tradicionais na arena de lutas.

A absorção de lideranças populares acarreta na inserção de mais um agente na arena de lutas, tencionando o campo de forças e o equilíbrio instável sobre o qual o Estado se assenta além de trazer mais um discurso político e ideológico (explícito ou implícito) de gestão urbana e assinalar temas da luta popular na agenda dentro do tempo-espaço da política pública.

33 Se tal processo de absorção permitiu o aparecimento de gestores comprometidos e engajados em determinadas lutas, como a Reforma Urbana, que vem da militância de movimentos populares, e não apenas de movimentos políticos partidários, análises futuras deverão apontar. Da mesma forma, a inserção de temas da luta popular nos aparelhos de Estado entra na engrenagem da burocratização e no escopo do enquadramento de políticas públicas. Há, em realidade, uma contradição no horizonte da gestão democrática: se, por um lado, há o empoderamento de grupos e frações das classes populares em novos canais de participação, há, por outro lado, uma fragmentação no campo da luta gerado pela absorção ${ }^{17}$ de lideranças de movimentos populares tornados quadros políticos (Cargos de Confiança (CCs) / Cargos Comissionados).

34 A luta reivindicatória se torna institucional e se realiza em etapas de um novo processo absorvido, incorporado e controlado pelo Estado. Para o caso da política urbana e habitacional, a grande aproximação do PT com movimentos populares de moradia transformou lideranças em gestores de uma máquina pública municipal, estadual ou nacional, isto é, gestores de aparelhos de Estado e responsáveis diretos pela promoção (ou não) de políticas públicas (LOPES, BUONFIGLIO e ÁVILA, 2013).

Isso significa um novo fenômeno que é preciso compreender no Brasil contemporâneo, que é a maior presença de membros e frações das classes populares no Estado, mas não de forma subalterna, como o "pessoal técnico" apontado por Poulantzas (1985), mas, governando o país ${ }^{18}$.

Para a teoria do Estado, a presença das classes populares não configura necessária, nem automaticamente, a institucionalização de um poder das classes populares no bojo do Estado. Mesmo para o caso de uma mudança da relação de forças e da modificação do poder de Estado em favor das classes populares, para Poulantzas (1985), o Estado tende, a curto ou longo prazo, a restabelecer sob nova forma a relação de forças em favor da burguesia.

37 Para L. Althusser (1998), não basta à classe dominante deter o poder de Estado (seja por meio de alianças de classe ou de fracções de classes) e, por consequência, dispor do aparelho repressivo de Estado (polícias, sistema prisional, etc), ela precisa exercer sua hegemonia de forma perene no tempo naqueles aparelhos ideológicos da sociedade civil (Igreja, Escolas, sistemas, Universidades, Meios de Comunicação): “A partir do que sabemos nenhuma classe pode duravelmente deter o poder de Estado sem exercer simultaneamente a sua hegemonia sobre e nos Aparelhos Ideológicos de Estado (ALTHUSSER, 1998, p. 48-49)".

Esse novo contexto brasileiro também exige o necessário abandono e superação do dualismo Estado/Sociedade Civil em prol da invenção de novos instrumentos analíticos, bem como do desenvolvimento de estratégias políticas mais eficazes, como sugere B. Sousa Santos (2011). Em realidade, como aponta o autor, a dicotomia Estado/Sociedade Civil pode ser caracterizada como uma absorção recíproca e constante de um pelo outro. 
39 E de toda forma, não se ignora que novos protagonistas e minorias ganharam visibilidade nas políticas públicas, com canais abertos de participação popular, instituição de fóruns, redes, articulações entre sociedade civil e poder público. Com o estabelecimento de novos espaços públicos não estatais, pode-se falar de uma redefinição de relações entre a sociedade civil e o Estado, trazendo novos elementos para essa clássica dicotomia, garantindo para a sociedade civil novas fontes de legitimação, nas quais têm lugar os poderes de fato (BOBBIO; 1982; 1986).

40 As Conferências Nacionais são o produto dessa redefinição de relações entre a sociedade civil e o Estado. Nelas se gesta a ampliação da democracia participativa contribuindo para a construção de Políticas Públicas no Brasil, trazendo à tona a multidimensionalidade do conflito político, fortalecendo a democracia representativa em seu conjunto:
As Conferências Nacionais são um meio eficiente de se resgatar a multidimensionalidade do conflito político. O papel delas é justamente o de, mediante práticas participativas e deliberativas, estruturar o processo decisório em torno de temas fundamentais (...) que embora eventualmente endossados por membros dos ministérios, não fazem parte do pacote de políticas considerado prioritário pelo governo. Assim, as Conferências, ao formularem diretrizes de políticas e comunicá-las à sociedade e ao Congresso, permitem que a multidimensionalidade da política retorne à cena, mas de maneira estruturada sem expor o Legislativo aos ciclos de decisão majoritária. (POGREBINSCHI, 2010, p. 29).

Enquanto políticas públicas para intervenção no território, as Conferências, em suas diversas escalas, permitem "conhecer as realidades locais, estaduais, regionais e estabelecer programas que atendam às especificidades sociais e territoriais", propiciando a articulação de frentes e de diversos segmentos da sociedade civil, "como um espaço de encontro e de trocas", bem como a "formação de redes de informação e difusão dos problemas a serem enfrentados" (RODRIGUES, 2010, p. 2).

O primeiro ano da gestão do Ministério das Cidades se encerra com a $1^{\text {a }}$ Conferência Nacional das Cidades, fórum deliberativo e marco histórico na luta da Reforma Urbana, quando se lançam as bases na construção coletiva e democrática para uma política nacional urbana. $\mathrm{Na} 1^{\text {a }}$ Conferência, ocorreu a eleição do Conselho Nacional das Cidades, outro importante espaço político constituído por um órgão colegiado de natureza deliberativa e consultiva ${ }^{19}$. O Conselho, instituído em 2004, para assegurar uma gestão mais democrática e menos centralizada pelo Poder Executivo é a típica esfera pública que amplia o espaço estatal e possibilita uma arena de lutas, moldado com base na gestão do direito à cidade.

Contudo, o Conselho das Cidades é composto por agentes com poderes contraditórios que o configuram como uma unidade conflitual de aliança de poder: o poder público nas três instâncias (municipal, estadual e federal), movimentos populares, entidades profissionais, acadêmicas e de pesquisa, ONGs, entidades sindicais e empresários.

Se as Conferências Municipais, Estaduais e Nacionais das Cidades aprovam e referendam propostas e diretrizes para a política urbana nacional, o Conselho Nacional das Cidades, por sua vez, deve fiscalizar e implantar tais propostas ${ }^{20}$. A adoção de estruturas normativas participativas visa reequilibrar poderes dentro da arena de lutas e faz um contraponto ao Legislativo. Deve-se ressaltar a importância de diretrizes de caráter legislativo e não simplesmente administrativo, isto é, resoluções que demandam tratamento com intervenção legislativa de forma expressa: exigem a elaboração, alteração ou regulamentação da legislação federal ou da Constituição, ou ainda, de outro ato normativo (como emenda constitucional) pelo Congresso Nacional ou de forma 
implícita (demandas cuja satisfação requer elaboração legislativa de temas de competência do Congresso Nacional (POGREBINSCHI, 2010) ${ }^{21}$.

As diversas Conferências das Cidades realizadas introduziram no debate político os temas trazidos por novos atores beneficiando indiretamente os indivíduos e grupos ausentes no debate, invisíveis na cidade ou que simplesmente ignoram tais eventos porque as Conferências "colocam em destaque as necessidades da maior parcela da população", justamente daqueles "grupos que não recebem os benefícios da produção da riqueza" (RODRIGUES, 2010, p. 2).

Entretanto, restam muitas inquietações e dúvidas quanto ao futuro do Estado Brasileiro: a configuração e materialidade institucional voltadas às políticas públicas para as classes populares serão suficientes para alguma mudança estrutural radical?

47 A mediação política desse processo de institucionalização, pela inserção de novos agentes sociais no interior dos aparelhos estatais, reequilibraria a "balança" da justiça social em prol das massas e classes populares, historicamente dominadas? A constituição de um processo mais amplo e democrático seria suficiente para alterar as relações de força no Estado Brasileiro? A nova aliança de poder será inclusiva, a ponto de restabelecer um novo padrão social de democracia com efetivo e elevado grau de abertura e participação popular? $\mathrm{O}$ atendimento social da habitação em escala, combinada com outras políticas sociais, como as cotas, o Bolsa Família, etc., ratificados como compromisso histórico, alterará a desigualdade social do país?

Na perspectiva dos autores aqui analisados, o Estado Brasileiro pode ser apreendido como um campo aberto repleto de possibilidades de ação, capaz de escutar diferentes orientações e constelações de interesse. Da mesma forma, o desenvolvimento e o futuro do capitalismo permanecem em aberto, não estão dados irremediavelmente e nem são determinados a priori, mas condicionados à ação social por meio de lutas e estratégias políticas (HIRSCH, 2010).

Essa recomendação de J. Hirsch nos leva ao campo de possibilidades de que fala Boaventura Sousa Santos (2011), que é justamente a tarefa da teoria crítica que não pode apenas aceitar a realidade existente, sob pena de reduzi-la, pensando que se esgotaram as alternativas, quando estas podem e devem superar o que é criticável no que existe.

\section{Breves Conclusões}

50 Na última década, assistiu-se uma transformação no Brasil que se faz necessário entender mais detidamente e que aqui analisamos em diálogo com à teoria marxista do Estado. Longe da pretensão de esgotar a realidade complexa da política brasileira, este artigo buscou um debate em sintonia com o momento político vivido no Brasil, trazendo alguns elementos sociais, políticos e econômicos da última década em um esforço de esboçar provisoriamente um ensaio da teoria do Estado brasileiro do período.

51 Da perspectiva de mudanças sociais e políticas, nos debruçamos sobre a relação do Estado com as classes populares; a penetração de antigas lutas e demandas populares no seio do Estado pautando contraditoriamente a construção de políticas sociais por meio de aparelhos estatais heterogêneos; do realinhamento político de representantes da fração de uma classe denominada subproletariado se não identificados com uma classe operária (trabalhadora em sentido amplo), ao menos identificados simbolicamente com Lula, no 
fenômeno apontado como lulismo; da emergência de novos atores sociais e políticos constituindo novas arenas de luta; da absorção de atores sociais nos aparelhos estatais.

No plano da política macroeconômica brasileira, o período da última década fora marcado por disputas intensas de interesses de grupos e frações capitalistas no interior do bloco no poder, com destaque para a fração bancário-financeira cuja queda de braço se traduzia ora no fortalecimento da ortodoxia neoliberal, ora no fortalecimento da ala desenvolvimentista. Esta ultima ala foi determinante para driblar a crise financeira internacional com a formulação de programas nacionais como o Programa de Aceleração do Crescimento (PAC) e o Minha Casa, Minha Vida (MCMV). Alguns elementos são apontados como a queda da taxa Selic e a redução das taxas de juros dos bancos públicos que alguns autores chamaram de heterodoxia econômica. De toda forma, velhas e novas correntes possibilitaram novas composições de forças do bloco no poder do Estado Capitalista Brasileiro.

53 As agendas política, social e econômica seguem em aberto a partir dos compromissos antagônicos que o Estado toma para si e do jogo de relação de forças entre classes dominantes e populares.

\section{BIBLIOGRAFIA}

ALTHUSSER, Louis. Ideologia e Aparelhos Ideológicos do Estado. Trad. Joaquim José de Moura Ramos. São Paulo: Martins Fontes,1970. (Versão digital).

BELLUZZO, L. Gonzaga. As proezas da finança capitalista. Carta Maior, [online], 2014. Disponível em: http://www.cartamaior.com.br/?/Editoria/Politica/As-proezas-da-financa-capitalista/. Acesso em: 16/09/2014.

BOBBIO, Norberto. Estado, governo e sociedade - para uma teoria geral da política. Rio de Janeiro: Paz \& Terra, 1986.

O conceito de sociedade civil. Rio de Janeiro: Graal, 1982.

BONDUKI, Nabil. Avanços, Limitações e Desafios da Política Habitacional do Governo Lula Direito à Habitação em oposição ao direito à cidade. In: Fernandes, Edésio; Alfonsin, Betânia. (Coords.). Direito à Moradia Adequada: o que é, para quem serve, como defender e efetivar. Belo Horizonte: Fórum, 2014. p. 293-316.

CARNOY, Martín. Estado e Teoria Política. 2. ed. Campinas: Papirus, 1988.

CHAUÍ, Marilena. Uma Nova Classe Trabalhadora. In Emir Sader (org.). "10 anos de Governos PósNeoliberais no Brasil: Lula e Dilma”. São Paulo, SP: Boitempo; Rio de Janeiro: FLACSO Brasil 2013.pp. 123-134

COIMBRA, Marcos. Quatro Razões para a Vitória de Lula. Cadernos Fórum Nacional, INAE, Rio de Janeiro, n. 6, fev. 2007.

ENGELS, Friedrich. Origem da Família, da Propriedade Privada e do Estado. Rio de Janeiro: BestBolso, 2014. 223p 
HIRSCH, Joachim. Teoria Materialista do Estado. Rio de Janeiro: Revan, 2010.

LOPES, Cledir da C; BUONFIGLIO, Leda V.; ÁVILA, Gilmar. Gestão Democrática. Violações ao Direito à Cidade e à Moradia decorrentes de Megaprojetos de Desenvolvimento no Rio Grande do Sul. Diagnóstico e Perspectivas - O Caso de Rio Grande. Porto Alegre: CEDES, Centro de Direitos Econômicos e Sociais, 2013. (Volume 1).

MARETTI, Eduardo. Entrevista com Boaventura Souza Santos. Rede Brasil Atual, [online], 12.09.2014. Disponível em: http://www.redebrasilatual.com.br/politica/2014/09/para-sociologoportugues-direita-trocou-aecio-por-marina-e-candidata-e-e-ameaca-em-muitos-niveis-6188.html . Acesso em: 14/09/2014.

PAULANI, Leda. Terrorismo Econômico. Blog da Boitempo, (s/l), 20.10.2014. Disponível em: < http://blogdaboitempo.com.br/2014/10/20/leda-paulani-terrorismo-economico/>. Acesso em: 20/10/2014.

POCHMANN, Marcio. Nova Classe Média? O trabalho na base da pirâmide social brasileira. São Paulo: Boitempo, 2012.

POGREBINSCHI, Thamy. (Coord.). Entre Representação e Participação: as conferências nacionais e o experimentalismo democrático brasileiro.Rio de Janeiro: IUPERJ; Secretaria de Assuntos Legislativos do Ministério da Justiça (SAL/MJ); Programa das Nações Unidas para o Desenvolvimento (PNUD), 2010. (Versão digital).

POULANTZAS, Nico. O Estado, o Poder, o Socialismo. 2. ed. Rio de Janeiro: Edições Graal, 1985.

RODRIGUES, Arlete Moysés. Apresentação: Conselho das Cidades. Uma Avaliação das Conferências. IV Conferência Nacional das Cidades, Ministério das Cidades, Brasília, 19 a 23 de junho de 2010.Disponível em:http://www.agb.org.br/documentos/

Arlete_Avaliacao_IV_Conferencia_das\%20Cidades_2010.pdf.

SADER, Emir. A Vingança da História. 2. ed. São Paulo: Boitempo, 2007.

SCHWASBERG, Benny. Planejamento Urbano no Brasil pós-1988: panorama histórico e desafios contemporâneos. In: FARIA, Rodrigo de; SCHWASBERG, Benny. (Orgs.). Políticas Urbanas e Regionais no Brasil. Brasília: Universidade de Brasília/Faculdade de Arquitetura e Urbanismo, 2011.

SINGER, André. Raízes Sociais e Ideológicas do Lulismo. Novos Estudos, CEBRAP, São Paulo, n. 85, p. 82-103, novembro 2009 .

SINGER, Paul. Dominação e Desigualdade. Estrutura de classes e repartição da renda no Brasil. Rio de Janeiro: Paz e Terra, 1981.

SOUSA SANTOS, Boaventura de. A crítica da razão indolente. Contra o desperdício da experiência. Para um novo senso comum. A ciência, o direito e a política na transição paradigmática. 8. ed. São Paulo: Cortez Editora, 2011. (Volume 1).

Pela Mão de Alice: O social e o político na pós-modernidade. São Paulo: Cortez, 1995.

TEIXEIRA, Rodrigo A. Rentismo, Fissuras no Bloco do Poder e as Eleições Presidenciais. Carta Maior, [online], 05.09.2014. Disponível em: http://www.cartamaior.com.br/?/Editoria/Politica/ Rentismo-fissuras-no-bloco-no-poder-e-as-eleicoes-presidenciais/4/31749. Acesso em: 05/09/2014.

VAINER, Carlos B. Cidade de exceção: Reflexões a partir do Rio de Janeiro. (versão digital, s/d). Site do Ministério Público Federal (MPF). Disponível em:http://pfdc.pgr.mpf.gov.br/atuacao-e- 
conteudos-de-apoio/publicacoes/direito-a-moradia-adequada/artigos/cidade-de-excecao-carlosvainer/view. Acesso em: 17/05/2013.

WHITAKER, João. Uma revolução geracional. Brasil Post, [online], 24.02.2014. Disponível em: http://www.brasilpost.com.br/joao-whitaker/uma-revolucao-geracional_b_4814570.html? utm_hp_ref=brazil. Acesso em:24/02/2014.

\section{NOTAS}

1. Foi assim que Lula perdeu para Fernando Collor (ano 1989) e para Fernando Henrique Cardoso (ano 1994 e 1998), não pelo voto dos mais ricos, mas justamente, ao contrário, pelos votos dos mais pobres, devido à mobilização dos eleitores de menor renda contra a esquerda.

2. Texto de Marcos Coimbra: "Quatro Razões para a Vitória de Lula", Cadernos Fórum Nacional, № 6, fev 2007. p. 6-13.

3. Dentro dessa condensação de forças, há as classes dominantes com o bloco no poder representadas por várias frações da classe burguesa - capital monopolista e não monopolista - e mesmo de outras classes, como os proprietários de terra. Há, claro, contradições internas ao bloco no poder.

4. Criado em 2004, o crédito consignado permitiu aos bancos descontar empréstimos em parcelas mensais retiradas diretamente da folha de pagamentos do assalariado ou do aposentado. A redução do risco decorrente do pagamento garantido acarretou uma queda em quase treze pontos percentuais da taxa de juros, e, em 2005, depois de crescer quase $80 \%$, o crédito consignado colocava em circulação dezenas de bilhões de reais, usados, em geral, para o consumo popular.

5. Artigo digital / blog de João Whitaker “Uma Revolução Geracional”. Disponível em: http:// www.brasilpost.com.br/joao-whitaker/uma-revolucao-geracional_b_4814570.html?

utm_hp_ref=brazil. Acesso em: 24/02/2014.

6. “As contradições presentes entre as frações do bloco no poder se condensam nas divisões e contradições internas ao Estado, entre seus vários ramos, redes e aparelhos e no interior de cada um deles" (Carnoy, 1988, p. 161).

7. Citado por Eduardo Maretti (2014). Artigo disponível em: http://www.redebrasilatual.com.br/ politica/2014/09/para-sociologo-portugues-direita-trocou-aecio-por-marina-e-candidata-e-eameaca-em-muitos-niveis-6188.html. Acesso em: 14/09/2014.

8. Como Marcio Pochmann questiona e traz para o centro da análise em seu livro: "Nova Classe Média? O trabalho na base da pirâmide social brasileira" (2012) as peculiaridades das ocupações (emprego de baixa remuneração) na base da pirâmide não poderiam estar associadas ao conceito de classe média ascendente. $O$ autor prefere enquadrar tal segmento social na categoria analítica de trabalhadores pobres (working poor).

9. R. A. Teixeira está se referindo ao ministro da Fazenda, Antonio Palocci, "o grande fiador de Lula diante da elite econômica e em especial do mercado financeiro". Tal hegemonia financeira possibilitava que a fração bancário-financeira "determinasse os rumos da política econômica, ancorada no sucesso ideológico de seu discurso, abraçado incondicionalmente pela mídia, bem como na constante chantagem das fugas de capital" (TEIXEIRA, 2014, s/p).

10. Editorial da Revista Carta Maior. "Fissuras No Bloco no Poder e as Eleições Presidenciais" (TEIXEIRA, 2014, s/p).Disponível em: http://www.cartamaior.com.br/?/Editoria/Politica/ Rentismo-fissuras-no-bloco-no-poder-e-as-eleicoes-presidenciais/4/31749. Acesso em: 05/09/2014.

11. A teoria marxista do estado herdou o conceito gramsciano de hegemonia: é o exercício da ideologia da classe dominante; é o meio pelo qual a classe dominante conquista o consentimento 
das massas populares para sua dominação social. A hegemonia se torna uma importante síntese do pensamento gramsciano: é o exercício do consentimento (no sentido de submissão das classes populares aos valores das classes dominantes) e a repressão pelos mecanismos tradicionais coercitivos do Estado (Carnoy, 1988).

12. E. Sader e R. A. Teixeira retratam detidamente o papel do Ministério da Fazenda como "centro de gravidade do governo" Lula (SADER, 2007, p. 212) na figura do ministro Antonio Palocci, "o grande fiador de Lula diante da elite econômica e em especial do mercado financeiro". Tal hegemonia financeira possibilitava que a fração bancário-financeira "determinasse os rumos da política econômica, ancorada no sucesso ideológico de seu discurso, abraçado incondicionalmente pela mídia, bem como na constante chantagem das fugas de capital" (TEIXEIRA, 2014, s/p).

13. O PMCMV rendeu a manutenção da Secretaria de Habitação como a única de sua formação original dentro do Ministério das Cidades em um processo de desarticulação política simultâneo à criação de condições econômicas favoráveis às políticas urbanas analisada por N. Bonduki: "se as condições econômicas eram favoráveis em linhas de ações estruturantes, do contrário, as condições políticas eram desfavoráveis e culminaram na desarticulação das políticas urbanas do Ministério das Cidades que "ainda buscava se estruturar para exercer seu papel de formulador da política urbana para o país” (BONDUKI, 2014, p. 308).

14. A partir de agosto de 2011, o Banco Central inicia uma trajetória de queda da taxa Selic, até atingir o patamar de 7,25\%, com a taxa de juros real chegando à casa dos $2 \%$ em 2012, sob críticas do mercado financeiro e aplausos dos representantes do setor produtivo e dos trabalhadores. Além disso, vendo que aqueda da Selic não estava sendo repassada aos consumidores de crédito, em maio de 2012, a presidenta dá ordem expressa aos bancos públicos para reduzirem suas taxas de juros e forçar a redução dos spreads bancários, que estavam entre os mais altos do mundo. 0 momento mais simbólico foi o discurso da presidenta no 1.o de maio de 2012, Dia do Trabalhador, anunciando em cadeia nacional que os bancos públicos iam travar uma batalha pela redução dos spreads bancários (TEIXEIRA, 2014, s/p).

15. Artigo de Leda Paulani no blog da Boitempo, intitulado Terrorismo Econômico. Disponível em: http://blogdaboitempo.com.br/2014/10/20/leda-paulani-terrorismo-economico/ . Acesso em: $20 / 10 / 2014$.

16. Mesmo governando com um equilíbrio instável, o Estado precisa garantir a unidade do aparelho político com uma "relativa coerência e certa homogeneidade da política estatal". A questão da legitimidade sob o risco de uma "crise da autoridade", nos termos de Gramsci, e do abalo da hegemonia da classe dominante é um problema fundamental nos autores que trabalharam na perspectiva do Estado capitalista.

17. A adoção da expressão "absorção" em vez de cooptação nos parece mais compatível com a ideia de Estado permeável e não monolítico, que portanto não é externo à sociedade civil, como analisado em Poulantzas (1985) e Hirsch (2010).

18. 38 Os mecanismos de reprodução da relação dominação-subordinação são inerentes ao arcabouço material do Estado que asseguram a presença das classes populares em seu interior, mas exatamente como classes dominadas (Poulantzas, 1985).

19. O Conselho Nacional das Cidades é "um órgão colegiado de natureza deliberativa e consultiva, integrante da estrutura do Ministério das Cidades e tem por finalidade estudar e propor diretrizes para a formulação e implementação da PNDU, bem como acompanhar a sua execução". Disponível em: http://www.cidades.gov.br/index.php/o-conselho-das-cidades. Convém ressaltar que o Conselho das Cidades foi aprovado na $1^{\text {a }}$ Conferência Nacional das Cidades como instância deliberativa, no entanto, o Ministério da Fazenda não o aprovou enquanto tal. Portanto, a partir da $2^{\text {a }}$ Conferência Nacional em diante, sempre se recolocou a questão de o Conselho ser deliberativo. 
20. São três tipos de Resoluções: Recomendadas, Normativas e Administrativas. As primeiras são relativas aos atos de outras unidades administrativas das esferas do Poder Público e entidades da sociedade civil. As normativas são reservadas à regulamentação e normatização dos atos do ConCidades. E as últimas são as concernentes aos atos administrativos. Disponível em: http:// www.cidades.gov.br/index.php/resolucao-concidades.

21. 41 Apenas para ter uma ideia do clima de debate, a primeira Conferência Nacional das Cidades deliberou 25 diretrizes legislativas; na segunda, em 2005, foram encaminhadas 40 diretrizes e na terceira, ocorrida em 2007, 22 diretrizes sobre diversas questões urbanas.

\section{RESUMOS}

O presente artigo propõe um breve ensaio sobre o Estado Brasileiro da última década (2003 2013), buscando evidenciar alguns elementos econômicos, políticos e sociais que ensejam mudanças estruturais na realidade brasileira, estabelecendo pontos de apoio para um quadro teórico (ainda que provisório) no debate da teoria marxista do Estado, extrapolando uma análise da conjuntura.

This article proposes a brief essay on the Brazilian State over the last decade (2003 - 2013), seeking to bring out a few economic, political, and social elements leading to structural changes in Brazilian reality, and establish supporting points for a theoretical picture - albeit provisional in the debate of the Marxist Theory of the State, which exceeds a situational analysis.

El presente artículo se propone realizar un breve ensayo sobre el Estado brasileño de la última década (2003 - 2013), buscando evidenciar elementos económicos, políticos y sociales que muestran los cambios estructurales de la realidad brasileña, estableciendo puntos de apoyo para un cuadro teórico (aun en construcción) para el debate teórico marxista sobre el Estado, extrapolando un análisis de coyuntura.

Cet article propose un bref essai sur l'état brésilien de la dernière décennie (2003 - 2013) cherchant à mettre en évidence certains éléments économiques, politiques et sociaux qui entraînent des changements structurels dans la réalité brésilienne, en établissant des points de soutien théoriques (bien que provisoires) dans le débat de la théorie marxiste de l'État, extrapolant une analyse de la conjoncture.

\section{ÍNDICE}

Mots-clés: État; des arènes de lutte; appareil d'état; politiques publiques.

Keywords: State; fighting arenas; state apparatuses; public policies.

Palabras claves: Estado; Arena de lucha; Aparatos Estatales; Políticas Públicas.

Palavras-chave: Estado; arenas de luta; aparelhos estatais; políticas públicas. 


\section{AUTOR}

\section{LEDA VELLOSO BUONFIGLIO}

Doutora em Geografia pela Universidade Estadual de Campinas (2015); mestre em Geografia pela Universidade de Brasília (2007) e geógrafa pela Universidade de São Paulo (2004). Desenvolve pesquisas especialmente em geografia urbana, com temas relacionados às políticas públicas de planejamento urbano e reestruturação e morfologia do espaço urbano. Professora Colaboradora do Programa de Pós Graduação em Geografia e Pesquisadora do Núcleo de Análises Urbanas (NAU), do Instituto de Ciências Humanas e da Informação (ICHI) da Universidade Federal do Rio Grande (FURG). E-mail: ledabuonfiglio@yahoo.com.br. 